\title{
Caregivers' Perceptions of Causes and Treatment of Fever and Diarrhea among Under-Fives in Ile Ife
}

\author{
T. E. Babalola ${ }^{1}$, K. T. Ijadunola ${ }^{2}$, T. T. Oyetoke ${ }^{1}$, K. O. Oyeniyi ${ }^{3}$, A. A. Shittu ${ }^{4}$ and S. A. Salawu ${ }^{5}$ \\ 1. Department of Paediatrics and Child Health, Obafemi Awolowo University Teaching Hospitals Complex, Ile-Ife, Osun State, \\ 220005, Nigeria \\ 2. Department of Community Health, Obafemi Awolowo University Teaching Hospitals Complex, Ile-Ife, Osun State, 220005,
} Nigeria

3. Department of Paediatrics, State Specialist Hospital, Asubiaaro, Osogbo, Osun State, 00176, Nigeria

4. Department of Surgery, University of Ilorin Teaching Hospital, Ilorin, Kwara State, 23401, Nigeria

5. Department of psychiatry, Lagos University Teaching Hospital, Idi-Araba, Lagos, 100254, Nigeria

\begin{abstract}
Introduction: Fever and diarrhoea account for a significant portion of under-five mortality in Nigeria. This might be related to the perceptions of caregivers on the causes, which could influence the treatment they proffer. The study was conducted among caregivers in Ife central Local Government. Results: Most mothers perceived that fever could be caused by malaria, teething, hot weather, cough and that diarrhea could be caused by teething, eating contaminated food, drink and water, dirty environment and feeding bottles. Illness behavior was poor, as most waited at least one day after the onset of symptoms before taking any action. Choice of treatment was mostly influenced by health education messages received from health workers and mass media. Discussion and conclusions: Caregivers had a fairly correct perception of the causes of fever, but had incorrect perceptions of the causes of diarrhea. There is need to educate caregivers on the causes of diarrhea, and appropriate treatment measures.
\end{abstract}

Key words: Caregivers, fever, diarrhea, perception.

\section{Introduction}

In 2015, under-5 mortality rate for Nigeria was 108.8 deaths per thousand live births. Nigeria ranks 173rd in childhood mortality worldwide [1]. Febrile conditions and diarrheal illnesses account for $>60 \%$ of under- 5 mortality in Nigeria [2]. A Nigerian child under the age of five has an average of 3 diarrhoea episodes each year, with 525,000 diarrhoea-related deaths [3].

The perception and intervention of children's caregivers has been shown to influence the child's care and overall outcomes, as certain disease-specific and non-disease-specific cultural beliefs may influence people's health seeking behavior [4].

With an unacceptable infant mortality rate in Nigeria,

Corresponding author: T.E Babalola, M.B.cH.B, bachelor of medicine and surgery, research fields: paediatric infectious disease, paediatric heamatology and oncology. and the need to improve this trend, an assessment of caregivers' perception is important. This study therefore set out to assess the perceptions of caregivers concerning the causes and the treatment modalities offered for fever and diarrhea among under-fives in Ile-Ife.

The aim of this study was to assess the perception of care givers on the causes and treatment options for fever and diarrhea among under-five children in Ife Central Local Government (LG) Area, Ile-Ife, Nigeria.

The specific objectives were to assess care givers' perceptions of the causes of fever and diarrhea among under-fives; to assess illness behavior of caregivers when under-fives have fever and diarrhea; and to Identify factors affecting caregivers' choice of treatment for fever and diarrhea among under-fives in Ife Central Local Government Area, Ile-Ife, Nigeria. 


\section{Materials and Methods}

\subsection{Materials}

This study was a descriptive, cross-sectional study, carried out in the Ife Central Local Government of Osun State over a 2-month period. Multi-stage sampling was done to select the caregivers, viz, a simple random sampling to select 4 out of the 11 wards in the LG, another simple random sampling to select a streets on each of the 4 wards, then a third simple random sampling to select a house, and if there was an under-5 in the house, the caregiver was thus selected and, if they consented, then were recruited into the study.

A questionnaire specially designed for the study, including socio-demographic data, the perceptions of causes, the preferred behaviour and treatment modalities adopted by caregivers in the event of fever and diarhoea; was administered to the caregivers by the researchers. Caregivers were asked to state 3 perceived leading causes of fever and diarrhea in their under-5 children; their 3 most likely stepwise actions in the event of fever and diarrhea in their children; as well as what influenced the actions taken.

\subsection{Statistic Analysis}

Collected data were analyzed using the Statistical Package for Statistical Solutions version 16, and results were expressed in means and percentages. Association between variables was assessed using the Chi-square and Fisher's exact tests where appropriate, and statistical significance was taken at $p<0.05$.

\section{Results}

There were 400 respondents in this study, 359 females (89.8\%) and 41 males (10.3\%). They were mostly Yorubas (90.5\%) with 6.5\% being Hausas and $2 \%$ were Igbos. The respondents were mostly married (80\%) and at least $90 \%$ had some form of formal education. The age-range between 25-34 years accounted for $61.8 \%$ of the respondents. Petty trading was the leading occupation of the caregivers (45\%), followed by artisans (21\%) and civil servants (15\%). As assessment of socio-economic status showed that only $15 \%$ of the caregivers earned above 50,000 naira monthly, although $11 \%$ did not state their monthly income.

The children of respondents in this study ranged between 6 months and 5 years (mean: $2.16 \pm 1.2$ years), and these caregivers were mostly mothers (78\%). Of these children, 350 (87.5\%) had fever in the last one year, while 272 (68.0\%) had diarrhea. The mean number of fever episodes over the previous year was $2.14 \pm 1.29$ while the mean number of diarrheal episodes was $1.78 \pm$ 1.06 .

Malaria (42.3\%) and teething (40.1\%) were the perceived leading causes of fever identified by caregivers in this study (Fig. 1); while Fig. 2 shows that teething was the perceived leading cause of diarrhea as shown by $52 \%$ of the caregivers followed by eating of contaminated food (25\%). The second leading cause of diarrhea as perceived by the caregivers is drinking of contaminated water (35\%) followed by eating of contaminated food (22.5\%)

The reported leading intervention by the caregivers in the event of fever was cold bath (50.5\%) and paracetamol administration (30\%); while oral rehydration solution (40.5\%) and antibiotics (15\%) were the leading reported interventions by the caregivers in the event of diarrhea.

About the influence for the actions of the caregivers in the event of fever, $40 \%$ of the caregivers reported routine health education as the sole influence for their actions, $25 \%$ stated fear of convulsion while $8 \%$ were influenced by advice from friends and relatives. Intervention by caregivers for diarrhea was influenced by health education (30\%), a desire to stop the diarrhea (24.5\%), as well as whether or not the child improved on current intervention (61\%).

In the last one year, $11.3 \%$ of caregivers took action on the day their children's fever began, 68.4\% took action the next day while $18.1 \%$ took action 2 days after. 


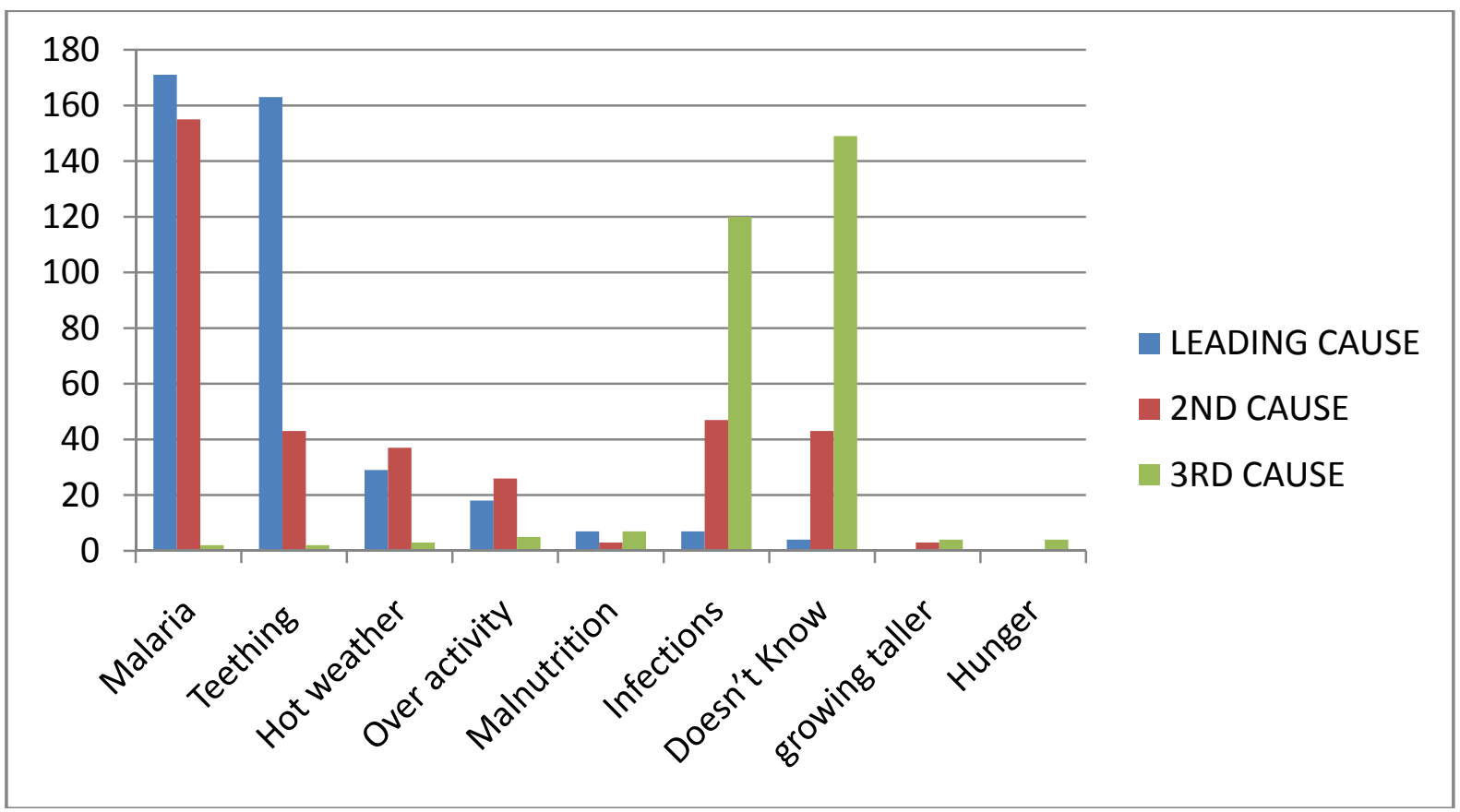

Fig. 1 Perceived leading causes of fever in the under-5.

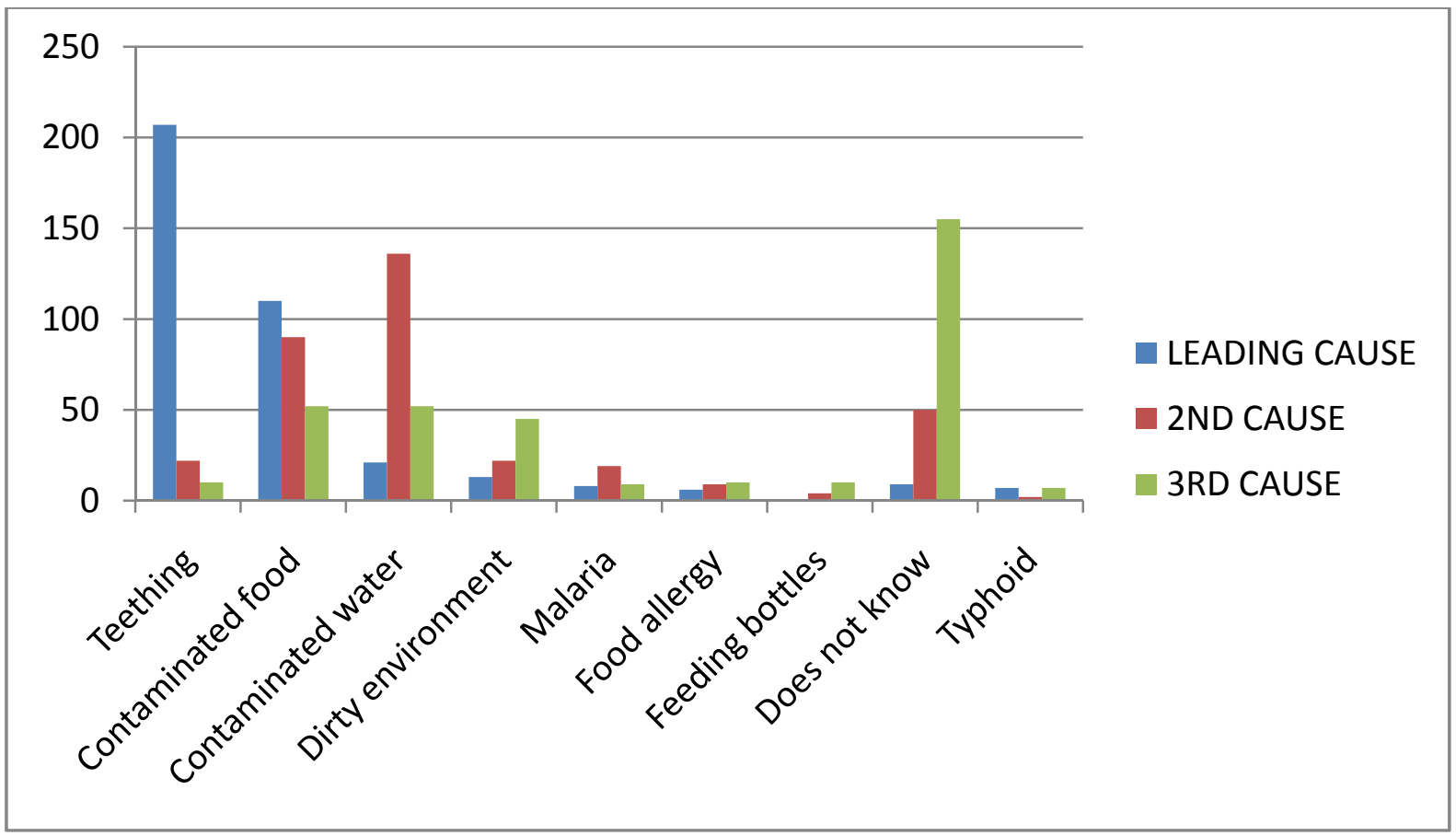

Fig. 2 Perceived causes of diarrhea in the under-5.

Of these, $55.1 \%$ of caregivers' children presented at a health facility, while $44.9 \%$ did not present.

Action was taken in the event of diarrhea on the same day in $2.1 \%$ of caregivers, $46.8 \%$ took action the day after, $39.4 \%$ acted 2 days after, while 12\% acted beyond 3 days after. Of these $48.2 \%$ presented at a health facility, while 51.8\% were treated at home. Also, $47.0 \%$ of the caregivers could correctly describe ORS preparation, $26.8 \%$ could not, while $26.2 \%$ did not know how ORS was prepared.

The relationship between educational status as well as the level of income; and the knowledge of causes of 
diarrhea was found to be statistically significant with $p$ value $=0.001$ and $p=0.009$ respectively, the timing of action for fever and diarrhea ( $p=0.001$ ), as well as the knowledge of ORS preparation was also found to be statistically significant with $p$ values of 0.039 and $p$ values of 0.002 respectively.

Gender was in addition, influence for what action was taken on fever and diarrhea, with women more likely to be influenced by advice from friends and relatives and men by health education $(p=0.001)$.

\section{Discussion}

Our results show a fair perception of causes of fever among caregivers, $42.5 \%$ in this study, a finding which is comparable to similar studies in Lagos [5] and in Port Harcourt [6]. Similarities in literacy levels and common childhood disease conditions might account for this, the high endemicity of malaria which is common knowledge may explain this. Also, it is notable that contaminated food and water were reported by caregivers in our study as causes of diarrhea, similar to findings from other parts of Raji et al. [7] in Sokoto, Nigeria, as well as from mothers in 2 markets in Ibadan [8]. This finding is important in the sense that this perception might help influence improvements in household hygiene by the caregivers as a means of preventing and managing diarrhea in the under-5 children.

Teething still is reported as a prominent cause of fever, as well as leading cause of diarrhea in this study. Several other studies have reported similar findings in mothers across the country and elsewhere. For example, Ige et al. [9] in Ibadan, showed that $52 \%$ of mother reported teething as a cause of fever, while Ozeigbe et al. [10] in Ife showed that $42.1 \%$ of mothers believed teething should be associated with fever.

To answer the question of the association between teething and fever, a meta-analysis of 16 studies by Massignan et al. [11] showed that, while teething may be associated with a rise in temperature, there is no evidence that tooth eruption causes fever. This fact is important, as it may delay definitive treatment for fever and its causes, and it may inform the use of non-effective treatments like the use of teething powder,

which has been met with ensuing complications, much that the United Kingdom Medicines and Healthcare products Regulatory Agency issued a teething powder warning in 2016, taking a cue from the United States Food and Drug Administration [12].

It is also noteworthy that a significant proportion of caregivers managed fever and diarrhea at home. This might help to reduce associated risks like convulsion or severe dehydration. However, the habitual use of anti-pyretics might delay presentation and definitive treatment of the cause of the fever or allow other complications (e.g. anemia) to develop. Mothers should thus be educated to present in time to health facilities if symptoms do not improve.

Educational status has been shown to be a strong influence for perception as well as action taken, with better action taken by the more educated. This underscores the importance of education of the girl-child, a future caregiver [13]; to make her better informed and empowered to care for her children and household.

Economic status also has a strong influence in this study, as education, place residence, wealth status and work status of women have a direct contribution to their decision making [14] Women empowerment, improved social-economic status and instituting free treatment of under-5 children might help reduce morbidity and mortality from common childhood illnesses in this age-bracket.

Male and female caregivers have been shown from this study to have slightly differing factors informing their actions. Stefan [15] studied 1,500 men and women and noted that women receive more informal health information from friends and relations than men did, similar to findings from our study. We might need to explore the gender-based differences in health information acquisition to thus 
improve the perception and knowledge of the caregivers, which might then help to make them better caregivers.

\section{Conclusions}

This study revealed a fairly good knowledge of fever among caregivers. Re-orientation of caregivers on teething in fever and diarrhea; the role of girl-child education, economic empowerment of caregivers and better health education are needed in our community. The above efforts will improve care for our under-fives. Some lines of future study include finding out how intervention has improved the perception of caregivers with wrong perceptions and treatment behavior.

\section{References}

[1] World Data Atlas. Nigeria-under-5 Mortality Rate USA: Knoema; 2017 [cited 2018 January 12]. Available from: www.knoema.com/atlas/topics/Health/Health-Status/Und er-5-mortality-rate?baseRegion=NG.

[2] United Nations Children’s Fund. Nigeria, Maternal and Child Health USA: United Nations Children's Fund; 2015 [cited 2017 December 2017]. Available from: www.unicef.org/nigeria/children_133.html.

[3] World Health Organisation. Causes of Child Mortality by Country, 2000-2010 USA: World Health Organisation; 2011 [cited 2018 January 10]. Available from: www.who.int/entity/gho/en.

[4] Abubakar, A., Van Baar, A., Fischer, R., Bomu, G., Gona, J. K., and Newton, C. R. 2013. "Socio-Cultural Determinants of Health-Seeking Behaviour on the Kenyan Coast: A Qualitative Study.” PLoS ONE. 8: e71998.

[5] Kazeem, A. O., and Idowu, O. S. 2008. "Fever in Children: Mothers' Perceptions and Their Home Management.” Iran J. Pediatr. 18: 229-36.

[6] Alex-Hart, B. A. and Frank-Briggs, A. I. 2011. "Mothers'
Perception of Fever Management in Children." The Nigerian Health Journal 11: 69-72.

[7] Raji, M. O., Abdullahi, U., Raji, I. A., Oladigbolu, R. A., Kaoje, A. U., and Awosan, K. J. 2017. "Caregivers' Knowledge, Home Treatment of Diarrhoea Disease and Predictors of Child Diarrhoea Disease in a Semi Urban Community of Sokoto, North-West, Nigeria.” Journal of Public Health and Epidemiology 9: 16-23.

[8] Omokhodion, F. O., Oyemade, A., Sridhar, M. K. C., Olaseha, I. O., and Olawuyi, J. F. 1998. "Diarrhoea in Children of Nigerian Market Women: Prevalence, Knowledge of Causes, and Management.” Journal of Diarrhoeal Diseases Research 16: 194-200.

[9] Olanrewaju, I. O., and Olubukola, P. B. 2013. "Teething Myths among Nursing Mothers in a Nigerian Community." Nigerian Journal of Medicine 54: 107-10.

[10] Oziegbe, E. O., Folayan, M. O., Adekoya-Sofowora, C. A., Esan, T. A., and Owotade, F. J. 2009. "Teething Problems and Parental Beliefs in Nigeria.” $J$ Contemp Dent Pract. 10: 75-82.

[11] Cardoso, C. M. M., Porporatti, A. L., Aydinoz, S., De Luca Canto, G., Mendonça Mezzomo, L. A., and Bolan, M. 2016. "Signs and Symptoms of Primary Tooth Eruption: A Meta-Analysis.” Pediatrics 137: e20153501.

[12] Parents Advised Not to Use Unlicensed Homeopathic Teething Products in Infants and Children [press release]. United Kingdom: United Kingdom Medicines and Healthcare Products Regulatory Agency, October 2016.

[13] Collins, E. N. O. 2014. "Socio-Economic Development and the Girl-Child Education: A Look at Jos North Local Government, Plateau State.” African Research Review 8: 134-55.

[14] Ibrahim, A., Tripathi, S., and Kumar, A. 2015. "The Effect of Women's Empowerment on Child Health Status: Study on Two Developing Nations.” International Journal of Scientific and Research Publications 5: 1-8.

[15] Ek, S. 2015. "Gender Differences in Health Information Behaviour: A Finnish Population-Based Survey.” Health Promotion International 30: 736-45. 